\title{
Karakteristik dan Pola Pengobatan Pasien Skizofrenia di Instalasi Rawat Inap RSJD Atma Husada Mahakam Samarinda
}

\author{
Helen Natalia Yuluci*, Nur Mita, Arsyik Ibrahim \\ Fakultas Farmasi Universitas Mulawarman, Samarinda, Kalimantan Timur \\ *Email: natalia_yuluci@yahoo.com
}

\begin{abstract}
ABSTRAK
Skizofrenia merupakan bentuk psikosis fungsional paling berat dan menimbulkan disorganisasi personalitas yang terbesar. Di Indonesia, penyakit skizofrenia berkisar antara 0,3-1\%. Penelitian ini bertujuan untuk mengetahui karakteristik pasien skizofrenia dan mengetahui pola pengobatan antipsikotik pasien skizofrenia. Metode ini dilakukan dengan pendekatan secara prospektif dengan menggunakan hasil observasi. Hasil penelitian karakteristik pasien skizofrenia menunjukkan mayoritas pasien berjenis kelamin laki-laki $(62,26 \%)$, usia pada masa dewasa awal, 26-35 (41,51\%), memiliki status perkawinan belum menikah $(29,25 \%)$, mayoritas jenis skizofrenia yang diderita adalah skizofrenia tak terinci $(54,72 \%)$, tidak memiliki pekerjaan $(88,68 \%)$, dengan lama gangguan 1-5 tahun $(65,09 \%)$. Terapi pengobatan antipsikotik yang sering digunakan dalam resep tunggal adalah antipsikotik atipikal, clozapin yang merupakan golongan dibenzodiazepin $(59,28$ $\%$ ), dan pada resep kombinasi yang paling sering digunakan adalah golongan tipikal dan golongan atipikal, kombinasi haloperidol dan clozapin $(36,4 \%)$. Pola ketepatan dosis untuk obat klorpromazin 100\% sesuai, trifluoresin 100\% sesuai, haloperidol $97,2 \%$ sesuai dan 2,8\% tidak sesuai, Clozapin 73,91\% sesuai, dan 26,09\% tidak sesuai, risperidon 96,3\% sesuai dan 3,7\% tidak sesuai. Berdasarkan hasil yang dapat disimpulkan, pasien skizofrenia akan diberi terapi antipsikotik generasi pertama, klorpromazin, triflurezin, haloperidol. Dan antipsikotik generasi kedua, clozapin dan risperidon.
\end{abstract}

\section{PENDAHULUAN}

Pada saat ini penderita dengan gangguan jiwa mengalami peningkatan jumlah terkait dengan berbagai permasalahan yang dialami oleh Bangsa Indonesia, mulai dari masalah perekonomian yang memburuk, masalah keluarga, latar belakang, atau pola asuh anak yang tidak baik, sampai bencana alam yang melanda negeri ini. Kondisi seperti ini dapat menimbulkan masalah-masalah psikososial dan ekonomi, yang dapat menimbulkan kecendrungan seseorang untuk mengalami skizofrenia. Orang yang mengalami skizofrenia menandakan kesehatan jiwanya terganggu, padahal kesehatan jiwa merupakan salah satu unsur kehidupan yang terpenting (Fausiah, 2005).

Keadaan ini pertama kali digambarkan oleh Kraepelin pada abad 1896 berdasarkan gejala dan riwayat alamiahnya. Kraepelin menamakannya dementia prekoks. Pada tahun 1911, Bleuler menciptakan nama skizofrenia untuk menandai terbelahnya atau putusnya fungsi psikis, yang menentukan sifat penyakit ini (Barbato, 1998).

Skizofrenia adalah gangguan psikiatrik kronis, termasuk gangguan mental yang sangat berat. Skizofrenia cukup banyak ditemukan di Indonesia, sekitar $99 \%$ pasien rumah sakit jiwa di Indonesia adalah orang dengan skizofrenia. Prevalensi orang dengan skizofrenia di Indonesia adalah $0,3 \%-1 \%$ dan biasanya dialami pada usia sekitar 18-45 tahun, bahkan ada juga pada usia 11-12 tahun sudah mengalami skizofrenia. Umumnya 
skizofrenia mulai dialami pada rentang usia 16-30 tahun dan jarang mulai terjadi diatas 35 tahun (Gingerich, 2006).

Skizofrenia menunjukkan manifestasi gangguan fungsi berpikir normal. Psikopatologi pada skizofrenia dapat digolongkan kedalam tiga dimensi, yaitu gejala positif, gejala negatif, dan disorganisasi. Gejala positif meliputi halusinasi, waham, gelisah, perilaku aneh, dan sikap bermusuhan. Gejala-gejala ini cenderung menyebabkan perawatan di rumah sakit dan menganggu kehidupan pasien. Gejala negatif meliputi efek tumpul atau datar, menarik diri, berkurangnya motivasi, miskin kontak emosional (pendiam, sulit diajak bicara), pasif, dan apatis.Gejala-gejala disorganisasi meliputi disorganisasi pembicaraan, disorganisasi perilaku, serta gangguan dalam pemusatan perhatian dan pengolahan informasi. Gejala ini dikaitkan dengan hendaya sosial dan pekerjaan pasien skizofrenia. (Kirkpatrick, 2005).

Pada American Pshchiatric Association (APA) telah dinyatakan bahwa perjalanan penyakit skizofrenia terdiri dari tiga fase yang satu sama lain dapat terjadi secara bersamaan. Fase pertama adalah fase akut yang ditandai dengan munculnya gejala positif dan gejala negatif, kemudian diikuti oleh fase stabilisasi yang ditandai dengan meredanya gejala, dan selanjutnya fase stabil yang ditandai dengan berkurangnya keparahan gejala dan stabilisasi. Sebagian besar pasien dapat mengalami peralihan berulang kali dari fase akut ke fases tabil diiringi oleh remisi total atau parsial dalam perjalanan penyakitnya (Wayne, 2007).

Menurut Wayne (2007), dasar pengobatan skizofrenia adalah medikasi dengan antipsikotik. Secara umum antipsikotik dibagi dalam dua kelompok besar, yaitu antipsikotik tipikal (antagonis reseptor dopamin) dan antipsikotik atipikal (antagonis serotonin dopamin). Pemilihan antipsikotik umumnya berdasarkan pada efikasi dan keamanan.

Tujuan utama dari terapi skizofrenia adalah mengembalikan fungsi normal pasien dan mencegah kekambuhan penyakitnya. Tidak ada pengobatan yang spesifik untuk masing-masing subtipe skizofrenia. Pengobatan hanya dibedakan berdasarkan gejala apa yang menonjol pada pasien. Penggunaan obat antipsikotik baik yang tipikal maupun atipikal merupakan pilihan terapi dan yang paling sering digunakan untuk mengobati gejala psikotik. Penggunaan obat tersebut terbukti memberikan perbaikan gejala dan mempertahankan pasien dari keberulangan (Lieberman, 2001).

Berdasarkan hal tersebut diatas, peneliti tertarik untuk mengetahui karakteristik pasien skizofrenia dan pola pengobatan terapi antipsikotik pasien skizofrenia di Instalasi Rawat Inap RSJD Atma Husada Mahakam Samarinda. Sehingga dengan adanya penelitian ini diharapkan dapat memperbaiki pelayanan kesehatan dan dapat menjadi pertimbangan dalam penggunaan antipsikotik agar pasien mendapatkan pengobatan yang efektif dan aman.

\section{METODE PENELITIAN}

Jenis penelitian ini adalah penelitian non eksperimental dengan analisa deskriptif dan pengambilan data dilakukan secara prospektif. Pengertian studi propektif adalah meneliti keadaan pasien dalam jangka waktu satu bulan dengan menggunakan data primer dan data sekunder untuk melihat karakteristik dan pola pengobatan terapi antipsikotik yang digunakan di Instalasi Rawat Inap RSJD Atma Husada Mahakam Samarinda. Sumber data primer yang diolah dalam penelitian ini adalah data hasil observasi penggunaan terapi antipsikotik pasien skizofrenia yang melakukan rawat inap di RSJD Atma Husada Mahakam Samarinda selama satu bulan (Februari-Maret). Instrumen penelitian yang digunakan berupa lembar pengumpul data yang memuat nomor rekam medis pasien, umur, jenis kelamin, tingkat pendidikan, status perkawinan, lama gangguan, jenis skizofrenia, 
obat yang digunakan dan dosis obatnya. Data yang diperoleh selanjutnya dianalisa secara deskriptif meliputi karakteristik pasien, persentase pemberian obat-obat antpsikotik apa saja yang masih diberikan pada pasien hepatitis, dan persentase ketidaksesuaian dosis yang terjadi di RSJD Atma Husada Mahakam Samarinda tersebut.

\section{HASIL DAN PEMBAHASAN}

Hasil pengolahan data menunjukkan bahwa jumlah pasien hepatitis yang menjalani rawat inap pada bulan Februar sampai Maret sebanyak 106 pasien. Rekam medik pasien yang memenuhi kriteria inklusi kemudian dianalisis karakteristik dan obat-obat antipsikotik apa saja yang diberikan pada pasien skizofrenia tersebut.

\section{Karakteristik subjek penelitian}

Berdasarkan tabel 1 dapat disimpulkan bahwa pasien berjenis kelamin laki-laki lebih banyak daripada pasien perempuan. Hal ini menyatakan bahwa laki-laki rentan terkena skizofrenia. Beberapa factor dapat menjadi penyebabnya, antara lain bahwa lakilaki lebih sering mengalami stress dibandingkan dengan perempuan, dan laki-laki juga lebh sering mengalami efek yang tidak menyenangkan dari stressor. Perempuan tidak rentan terkena skizofrenia, juga dapat disebabkan karena adanya hormon estrogen. Hormon ini menjadi factor protektif bagi pasien skizofrenia peempuan. Estrogen memiliki efek antipsikotika dan estrogen dapat melndungi pasien skizofrenia perempuan dari kerusakan otak.

Karakteristik pasien skizofrenia berdasarkan usia, dapat dilihat bahwa penderita skizofrenia terdapat pada kisaran usia 26-35 tahun. Usia ini berada dalam kategori masa dewasa awal. Pada pria gejala skizofrenia dapat terlihat pada usia 20 tahun, dan wanita pada usia 20 hingga 30 tahun. Usia masa dewasa awal merupakan masa transisi dan pencarian jati diri. Di usia ini, banyak hal yang dapat memicu timbulnya gejala skizofrenia, dimulai dari kondisi fisik atau kondisi lingkungan yang tidak nyaman. Selain itu, gejala skizofrenia akan tampak nyata apabila faktor biologis berinteraksi dengan faktor psikologis dan sosial.

Karakteristik pasien skizofrenia berdasarkan tabel, diketahui bahwa penyakit skizofrenia lebih banyak dialami oleh seorang individu yang belum menikah. Hal ini dikarenakan karena beberapa faktor, dimana individu yang telah menikah memiliki kualitas hidup yang baik dan tingkat interaksi sosial yang baik juga. Sedangkan individu yang tidak menikah, cenderung memiliki kehidupan yang kurang baik dan kemampuan sosialisasi yang buruk, serta hubungan emosional yang kurang baik.

Karakteristik pasien skizofrenia berdasarkan jenis skizofrenia, adalah jenis skizofrenia tak terinci. Hal ini dapat diakibatkan karena Karakteristik pasien skizofrenia berdasarkan pekerjaan, dapat dilihat bahwa mayoritas penderita skizofrenia merupakan individu yang tidak memiliki pekerjaan. Tidak memiliki pekerjaan juga menjadi salah satu onset timbulnya gejala skizofrenia. Dimulai dari stress yang berkepanjangan karena tuntutan hidup yang tidak terpenuhi hingga pengurungan diri dapat menjadikan individu mengalami gangguan kejiwaan. Bekerja dapat memperbaiki hubungan interaksi individu dengan individu lain.

Karakteristik pasien skizofrenia berdasarkan lama gangguan, dilihat bahwa ratarata pasien skizofrenia telah mengalami gangguan 1-5 tahun. Hal ini tidak lepas dari fakta yang menyatakan bahwa penyakit skizofrenia merupakan penyakit seumur hidup. Sehingga hal ini dapat diatasi melalui pengobatan yang tepat dan dukungan dari keluarga maupun lingkungan sekitar. 
Tabel 1 Karakteristik pasien Skizofrenia di Instalasi Rawat Inap RSJD Atma Husada Mahakam Samarinda

\begin{tabular}{|c|c|c|}
\hline Variabel & Jumlah & Persentase $\%(\mathrm{n}=106)$ \\
\hline \multicolumn{3}{|l|}{ Jenis Kelamin } \\
\hline Laki-Laki & 66 & 62,26 \\
\hline Perempuan & 40 & 37,74 \\
\hline \multicolumn{3}{|l|}{ Usia } \\
\hline $17-25$ & 12 & 11,32 \\
\hline $26-35$ & 44 & 41,51 \\
\hline $36-45$ & 36 & 33,96 \\
\hline $46-55$ & 11 & 10,38 \\
\hline $56-65$ & 3 & 2,83 \\
\hline$\geq 66$ & 0 & 0 \\
\hline \multicolumn{3}{|l|}{ Status perkawinan } \\
\hline \multicolumn{3}{|l|}{ Menikah } \\
\hline $17-25$ & 1 & 0,94 \\
\hline $26-35$ & 4 & 3,77 \\
\hline $36-45$ & 8 & 7,55 \\
\hline \multicolumn{3}{|l|}{ Belum Menikah } \\
\hline $17-25$ & 10 & 9,43 \\
\hline $26-35$ & 31 & 29,25 \\
\hline $36-45$ & 18 & 16,99 \\
\hline $46-55$ & 6 & 5,66 \\
\hline $56-65$ & 1 & 0,94 \\
\hline \multicolumn{3}{|l|}{ Duda/Janda } \\
\hline $17-25$ & 1 & 0,94 \\
\hline $26-35$ & 9 & 8,49 \\
\hline $36-45$ & 10 & 9,43 \\
\hline $46-55$ & 5 & 4,72 \\
\hline $56-65$ & 2 & 1,89 \\
\hline \multicolumn{3}{|l|}{ Jenis Skizofrenia } \\
\hline Skizofrenia Paranoid & 6 & 5,66 \\
\hline Skizofrenia Hebrefrenik & 3 & 2,83 \\
\hline Skizofrenia OBS & 14 & 13,21 \\
\hline Skizofrenia Tak Terinci & 58 & 54,72 \\
\hline Skizofrenia Psikotik & 8 & 7,55 \\
\hline Skizofrenia OBS Psikotik & 13 & 12,26 \\
\hline Skizofrenia Residual & 2 & 1,89 \\
\hline Skizofrenia Katatonik & 1 & 0,94 \\
\hline Skizofrenia Simplex & 1 & 0,94 \\
\hline \multicolumn{3}{|l|}{ Pekerjaan } \\
\hline Tidak Bekerja & 94 & 88,68 \\
\hline Bekerja & 12 & 11,32 \\
\hline \multicolumn{3}{|l|}{ Lama Gangguan } \\
\hline$<1$ bulan & 17 & 16,04 \\
\hline $1-5$ tahun & 69 & 65,09 \\
\hline 5-10 tahun & 9 & 8,49 \\
\hline$>10$ tahun & 11 & 10,38 \\
\hline
\end{tabular}


Tabel 2. Terapi antipsikotik tunggal pasien

\begin{tabular}{|c|c|c|}
\hline No & Jenis Obat & Persentase $(\%)$ \\
\hline \multirow[t]{3}{*}{1.} & Klorpromazin & 3,12 \\
\hline & Trifluoperezin & 6,25 \\
\hline & Haloperidol & 12,5 \\
\hline \multirow[t]{2}{*}{2.} & Clozapin & 59,38 \\
\hline & Risperidon & 18,75 \\
\hline & Jumlah pasien & 100 \\
\hline
\end{tabular}

Dari tabel 2 diketahui bahwa peresepan antipsikotik tunggal yang paling banyak diberikan adalah haloperidol. Hal ini dikarenakan haloperidol efektif menangani pasien dengan gejala positif, gaduh dan sulit tidur.

Tabel 3. Terapi antipsikotik kombinasi

\begin{tabular}{clc}
\hline No & \multicolumn{1}{c}{ Jenis Obat } & Persentase \\
\hline 1 & Risperidon-Klorpromazin & $13,7 \%$ \\
& Clozapin-Haloperidol & $36,4 \%$ \\
& Risperidon-Haloperidol & $4,5 \%$ \\
& Haloperidol- Klorpromazin-Risperidon & $4,5 \%$ \\
2 & Clozapin-Risperidon & $18,2 \%$ \\
3 & Haloperidol-Klorpromazin & $22,7 \%$ \\
\hline & Jumlah & $100 \%$ \\
\hline
\end{tabular}

Dari tabel 3 diketahui bahwa peresepan obat secara kombinasi yang paling banyak diberikan adalah kombinasi haloperidol dan clozapin. Hal ini dikarenakan haloperidol yang efektif untuk pasien gadul dan sulit tidur, dengan penambahan clozapin keadaan pasien menjadi lebih stabil. Dimana gejala positif ditangani oleh haloperidol, sedangkan clozapin dapat menangani gejala negatif yang timbul.

Tabel 4. Kesesuaian dosis terapi antipsikotik

\begin{tabular}{llcc}
\hline \multirow{2}{*}{ No. } & \multirow{2}{*}{ Jenis Obat } & \multicolumn{2}{c}{ Keterangan } \\
\cline { 3 - 4 } & & Sesuai & Tidak sesuai \\
\hline \multirow{2}{*}{ Klorpromazin } & 100 & 0 \\
& Trifluoperezin & 100 & 0 \\
& Haloperidol & 97,2 & 2,8 \\
2 & Clozapin & 73,91 & 26,09 \\
& Risperidon & 96,30 & 3,70 \\
\hline
\end{tabular}

Dari tabel 4 diketahui bahwa klorpromazin dan trifluoperazin telah diresepkan sesuai dengan dosis lazim. Sedangkan haloperidol 97,2\% sesuai dan 2,8\% tidak sesuai. Clozapin sesuai $73,91 \%$ dan 26,09 tidak sesuai. Risperidon $96,30 \%$ sesuai dan $3,70 \%$ tidak sesuai. 


\section{KESIMPULAN}

1. Karakteristik pasien skizofrenia adalah laki-laki, usia 26-35 tahun, belum menikah, skizofrenia tak terinci, tidak memiliki pekerjaan, dan mengidap skizofrenia1-5tahun.

2. Terapi tunggal antipsikotik paling banyak adalah clozapin.

3. Terapi kombinasi antipsikotik paling banyak adalah kombinasi haloperidol dan clozapin.

4. Pola pengobatan antipsikotik berdasarkan kesesuaian dosis. Klorpromazin dan trifluoresin $100 \%$ sesuai. Haloperidol $97,2 \%$ sesuai, clozapin $73,91 \%$ sesuai, risperidon $96,30 \%$ sesuai.

\section{DAFTAR PUSTAKA}

Barbato A. 1998. Schizophrenia and Public Health. World Health Organization: Geneva. Fausiah F.,\&Widury,J. 2005. Psikologi Abnormal KlinisDewasa. UI Press: Jakarta.

Gingerich K. 2006. Co-Morbidity of Schizophrenia and Substance Abuse Implication For Treatment. Journal of Conseling and Clinical Psychology.No.60 hal 845-856.

Krickpatrick B \& Tek C. 2005. Schizophrenia : Clinical Features and Phsycopathology in Kaplan \& Sadock (ed) Compherensive Textboox of Psychiatry, Eighty Edition , Lippincott William \& Wilkins, New York.

Lieberman JA, Murray RM. 2001. The Outcome of Psychotic Illness. Text Book Clinical Management: London.

Wayne S, Fenton. 2007. Schizophrenia: Integrated Treatment and Fuctional Outcomes Ed $8^{\text {th }}$. Koplan HI Sadock BJ: Philadelphia. 